\title{
A Conceptual Framework Outlining Factors Affecting the Acceptance of Earth as a Sustainable Building Material in the United Kingdom
}

\author{
By Mohammad Sharif Zami ${ }^{1}$
}

\begin{abstract}
Despite the fact that contemporary earth construction may open up new avenues to cutting down $\mathrm{CO}_{2}$ emissions, a review of literature reveals that there is sparse research to date identifying reasons behind why there may be resistance to earth construction as a sustainable construction material in the United Kingdom. The aim of this paper is to formulate a conceptual framework that facilitates a clearer understanding of factors affecting the acceptance of earth as a sustainable material in the UK. To achieve this aim, this study adopted a research methodological framework comprising of an extensive review of literature, the Delphi technique, and in-depth interviews. The conceptual framework provides insight into factors related to the UK context specifically including a lack of technological innovation, resources, well-established supply chain networks, training facilities in universities and building codes. These issues may be addressed through the promotion of earthen architecture as a method of cutting $\mathrm{CO}_{2}$ emissions and introducing earth construction modules in relevant degree programs.
\end{abstract}

Keywords: conceptual framework, factors, building material, earth, environmental sustainability

\section{Introduction}

According to Habert (2018), the construction industry has consumed two-fifths of the world's raw stone, gravel and sand resources and further depleted one quarter of the global supply of virgin wood. It further consumes $16 \%$ of the world's annual water supplies and $40 \%$ global energy while generating trillions of dollars on a global scale. In other words, trillions of dollars are generated to increase the profits of stakeholders at great cost to the environment. According to Reddy et al (2019), if we want to keep our global warming temperatures below $2{ }^{\circ} \mathrm{C}$ in the coming centuries, then as a measure of mitigating climate change we need to cut down global footprints from building resources and energy used by half. Yet in the context of the UK, the construction industry faces a complex series of interrelated factors that make mitigating climate change challenging. However, building projects require cooperation and agreement across all stakeholders, and influence over each group is required in order to successfully complete a project. It is not possible, for example, to change the architectural, engineering or regulatory structure of a project independently; rather, everything must change simultaneously. Given the complex relationships between conflicting factors and individuals, there is no quick solution to reducing the carbon footprint that the construction industry generates. Yet from within this context, greater awareness to protect the environment, particularly 
in the case of cutting down excessive $\mathrm{CO}_{2}$, has grown internationally and the concept of sustainable building has found center stage. Earth masonry, in particular, has regained popularity in recent years, and with current stabilization techniques, rammed earth wall and masonry units can be effectively used in load bearing construction (Jayasinghe, 2018).

Earth is spiritually connected with local cultures, provide shelter and supports life. On the other hand, cultures have taken advantage of earth material because it's resilient quality to withstand wider climatic variabilities (Reddy et al, 2019). However, in a wider global context, according to Reddy (2018), the inadequate availability of codes and performance standards prescribed by modern perception of building material has forced to reject the acceptance of indigenous earth buildings. Problems associated with the acceptance of earth building are numerous, multifaceted and difficult to resolve unless they are understood well. The aim of this paper is to formulate a conceptual framework that provides a clearer understanding of factors affecting the acceptance of earth as a sustainable form of material in the United Kingdom. A research methodological framework consisting of four stages was implemented to achieve this aim. First, a critical review of current literature was undertaken to outline factors affecting the acceptance of earth material and a working conceptual framework was formulated. The framework was then developed and validated through a group of international experts following the Delphi technique. A number of in-depth interviews further refined the conceptual framework with UK construction professionals that, as a result, lead to outline factors enacting earth as a sustainable building material in the UK.

\section{Literature Review on Factors Influencing the Acceptance of Earth Material}

The literature review on contemporary earth construction reveals a wide range of factors that may affect to enact earth as a sustainable building material. As represented in literature, these factors relate to benefits, drawbacks/inhibitors and drivers/enablers. Where beneficial factors are concerned, research suggests that earth building is advantageous under certain conditions (later presented in Figure 1), and upon fulfilling these conditions, the benefits are many, interdependent and they are presented in the Table 1.

Table 1: Benefits of contemporary earth constructions

\begin{tabular}{|c|c|}
\hline Advantages of earth as building material & \\
\hline 1. Use of earth is economically advantageous. & \multirow{9}{*}{$\begin{array}{l}\text { Lal, 1995, p. 119; Easton, } \\
\text { 1998; Morton, 2007; } \\
\text { Kateregga et al, 1983; } \\
\text { Cassell, 1993; Hadjri et al, } \\
\text { 2007; Morris and Booysen, } \\
\text { 2000; Adam and Agib, } \\
\text { 2001, p. 11; Maini, 2005; } \\
\text { Minke, 2006, p. 15; } \\
\text { Houben \& Guillaud, 1989; } \\
\text { Howieson, 2005; Alphonse } \\
\text { et al, 1985; Walker et al, }\end{array}$} \\
\hline ols and unskilled labour. & \\
\hline 3. It promotes housing construction in the & \\
\hline 4. It is & \\
\hline erial has low embodied energy; therefore, considered as & \\
\hline y balance interior temperature and humidity in an earth & \\
\hline 7. Earth displays very good resistance to fire. & \\
\hline & \\
\hline 9. Earth construction is envirc & \\
\hline
\end{tabular}


10. Earth walls preserve organic materials, such as timber.

2005, p. 43; Ngowai, 2000;

11. Earth walls (loam) absorb pollutants.

12. It is easy to design with and has high aesthetical value. Frescura, 1981; Zami, 2011; Zami, 2018.

13. Earth wall possess high insulation property, therefore, excellent in controlling noise.

14. Earth is local building material; therefore, it promotes heritage, tradition and cultural practice.

15. It is available worldwide in abundance.

Source: Author, 2020

Despite multiple benefits associated with contemporary earth construction, certain drawbacks and inhibitors negatively affecting use of earth material among practitioners and clients. Table 2 provides a summary of disadvantages (drawbacks and inhibitors) established from the literature. Furthermore, the terms 'drawbacks' and inhibitors' overlap throughout literature and are used interchangeably here.

Table 2: Drawbacks and inhibitors hindering earth building Disadvantages (Drawbacks and inhibitors) affecting use Authors of earth material

1. Earth material is not resistant to earthquakes, less durable, $\quad$ Kateregga, 1983; Lal, 1995, p. structurally inferior, and technically weaker.

2. Earth buildings require high maintenance and specialised skills for plastering.

3. Decreased fees from customary percentages on the overall expenditure of earth building.

4. Earth material is not standardised.

5. Suitability restricted to in situ construction and requires wider wall thickness.

6. Social stigma and inappropriate perceptions about earth material.

7. Understanding, knowledge, and skill is inadequate amongst professionals, governments and all stakeholders.

8. It is costly, time consuming and labour intensive.

9. Inadequate technologies and few resources

10. Inadequate number of courses and training on earth construction available in universities.

11. People are caring less for environment, comfort and value of aesthetics.

12. Absence of building codes and policies.

13. Difficulty in obtaining loans and insurance from financial authorities.

119; Cassell, 1993; Blondet \&

Aguilar, 2007; Maini, 2005;

Morris and Booysen, 2000;

Hadjri et al, 2007; Adam and

Agib, 2001, p. 11; Walker et al,

2005, p. 13; Robinson, 1939;

Morton 2007, p. 377; Norton

1997, p. 8; Chaudhury 2007;

Blondet and Aguilar 2007, p. 8;

Jagadish 2007, p. 26; Minke

2006, p. 18; Baiche et al 2008;

Sojkowski 2002; Morton 2007,

p. 383; Morton 2007, p. 379;

Jagadish 2007, p. 27; Houben et

al 2007, p. 39 ; Castells and

Laperal 2007; King 1996, p. 5;

Elizabeth 2005 ; Adams and

Elisabeth, 2005; Lal 1995, p.

124; Eisenberg 2005; Hadjri

2007, p. 143; Zami, 2014; Zami, 2018.

Source: Author, 2020.

In spite of the above drawbacks and inhibitors, a review of literature also indicates that certain drivers or enablers can help to accept earth material, as summarised in Table 3. 
Table 3: Adoption drivers for earth construction

\begin{tabular}{|c|c|}
\hline Drivers/enablers that help accepting earth material & Authors \\
\hline $\begin{array}{l}\text { 1. To promote earth building by the government, all } \\
\text { professionals, NGOs with the help of state medias. }\end{array}$ & \multirow{5}{*}{$\begin{array}{l}\text { Jagadish 2007, pp. 26-27; Morton } \\
\text { 2007, p. 377; Blondet and Aguilar } \\
\text { 2007, p. 9; Easton 1996, p. 19; } \\
\text { Elizabeth, 2005; Adams 2005; Baiche } \\
\text { et al 2008, p. 7; Norton 1997, p. 8; } \\
\text { Eisenberg 2005; Minke 2006, p. 196; } \\
\text { Jagadish 2007, p. 26; Houben et al } \\
\text { 2007, p. 39; Minke 2006, p. 196; } \\
\text { Castells and Laperal 2007, p. 100; } \\
\text { King 1996, p. 5; Zami, 2015; Zami, } \\
2018 .\end{array}$} \\
\hline 2. Formulate and adopt building codes of earth material. & \\
\hline $\begin{array}{l}\text { 3. Organising programmes on earth construction to train } \\
\text { engineers, contractors, labours and all building } \\
\text { workforce. }\end{array}$ & \\
\hline $\begin{array}{l}\text { 4. To introduce earth construction courses across in } \\
\text { architecture and civil engineering degrees. }\end{array}$ & \\
\hline $\begin{array}{l}\text { 5. Increase innovative construction and technologies } \\
\text { with earth material. }\end{array}$ & \\
\hline
\end{tabular}

Source: Author. 2020.

It is worth noting that economic benefits associated with earth construction are frequently mentioned in literature; yet earth as a construction material is also often characterised (structurally and technically) as a less durable and inferior material. According to Lal (1995), however, advancements in design and technology, including soil stabilisation, architectural design, and structural techniques can help resolve most drawbacks associated with earth buildings. No doubt, the drawbacks presented in Table 2, particularly those associated with experience limited to un-stabilised earth, can be addressed through research and innovation in contemporary stabilised earth construction.

While a critical review of literature presents an important overview of different factors (advantages, disadvantages and enablers) that may affect the acceptance of earth building, the factors identified in Tables 1, 2, and 3 lacking empirical evidence, especially where findings are based on author opinions or individual work experience as opposed to scientific research executed through reliable methodological processes. Furthermore, it appears that few studies to date have been carried out to prove whether these factors are valid or mere speculation. In some cases, researchers also appear to contradict one other. For example, in Table 1, which considers the benefits of earthen construction, the second factor states that earth construction requires simple tools and less skilled labour. On the other hand, in Table 2, which presents drawbacks to earth construction, the second factor states that earth requires specialised, skilled labour. In both cases, it is questionable whether these factors are the authors' perceptions, hypotheses or research outcomes.

It is important to highlight that the fifteen advantages of earth building identified in Table 1 and the thirteen disadvantages in Table 2 counterbalance, such as, claims in number 2 (in Table 1) and 8 (Table 2) conflicts; and ultimately cancel the disadvantage. Similarly, the thirteen disadvantages affecting the acceptance of earth material in Table 2 and five drivers identified in Table 3 also counterbalance. These counterbalances contribute to the development of an initial conceptual framework (Figure 1) designed to better understand which factors may be affecting the acceptance of earth material as an alternative solution to cutting excessive $\mathrm{CO}_{2}$ emissions. 

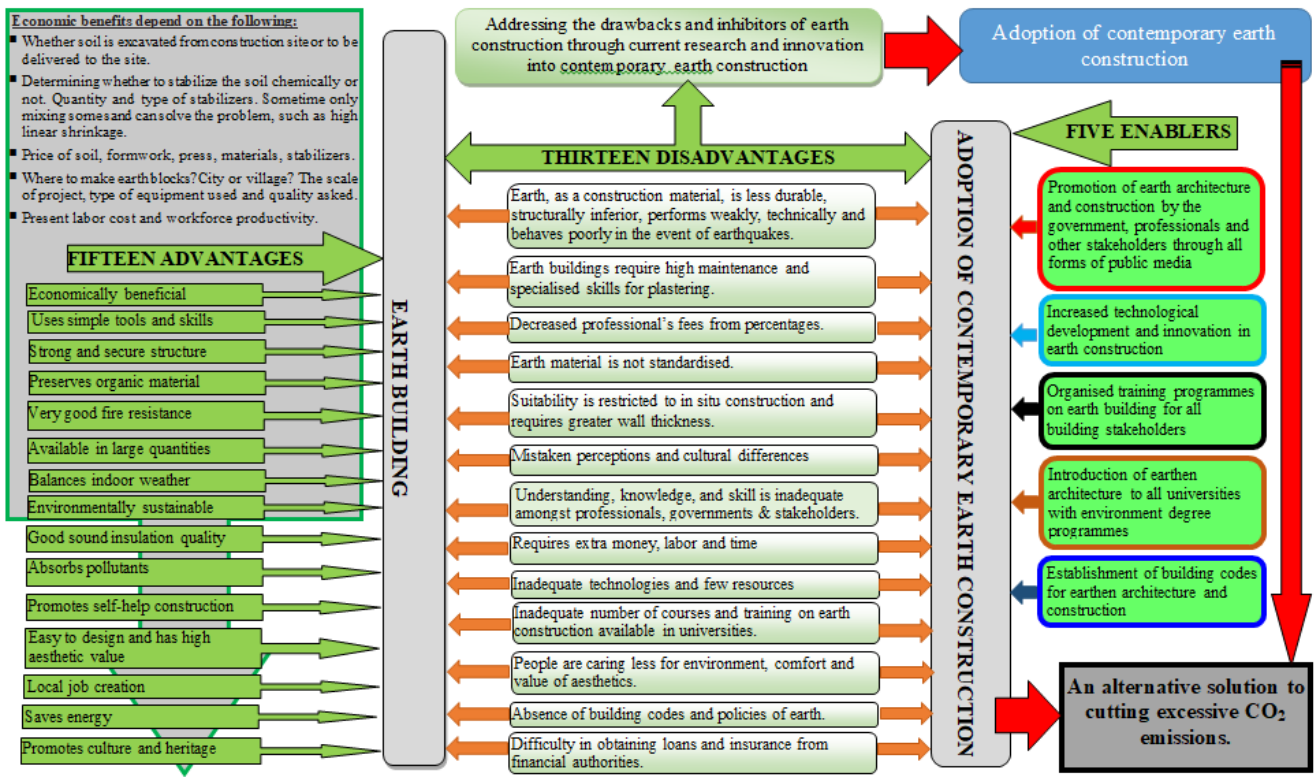

Figure 1: A conceptual framework (based on the literature review) of factors (advantages, disadvantages and enablers) affecting the acceptance of earth as a sustainable building material

Source: Author, 2020.

\section{Research Methodology}

An extensive literature search reveals a general absence of up-to-date structured study, conducted to outline which factors (advantages, disadvantages and enablers) may be affecting the acceptance of earth as a sustainable material in the United Kingdom. As noted, factors outlined by different authors in literature tend to represent perceptions alone, and thus lack validation through structured methodological processes. Therefore, the primary aim of this research is to provide a methodological framework that provides validity to the type of factors that may be affecting the acceptance of earth material in the UK.

In order to achieve this aim, a four-stage methodological framework (Figure 2) was employed:

- Stage One: Formulation of the research aim, objectives and methodological framework in light of the research gap identified in the literature review.

- Stage Two: Exploratory Phase (Delphi technique).

- Stage Three: Validation Phase (In-depth interview).

- Stage Four: Synthesis of the research process and outcomes. 


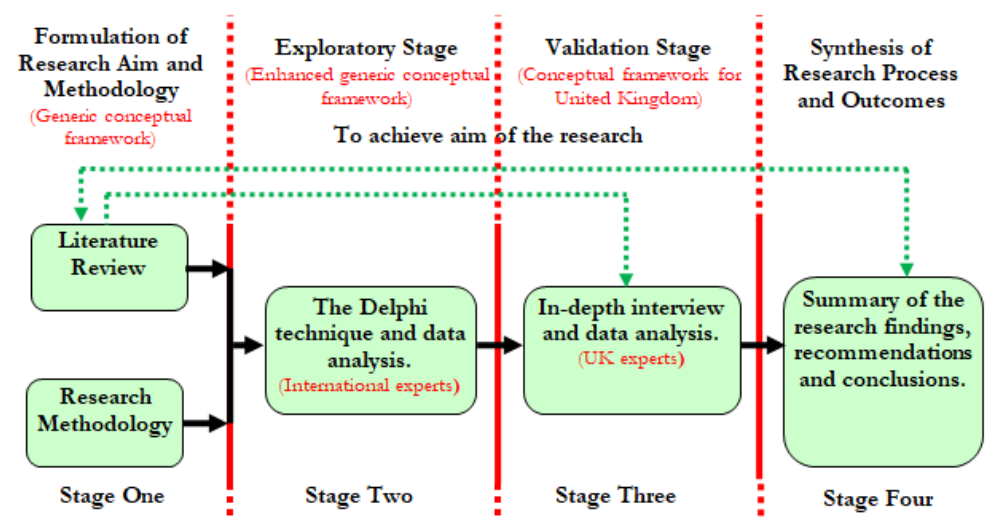

Figure 2: Methodological framework: A graphic representation of four interconnected stages and three techniques used in the study. Source: Author, 2020.

Stage One comprised a critical and comprehensive analysis (review) of literature related to acceptance earth material within the field of environmental sustainability. The results revealed that sparse studies have been pursued to outline and understand potential factors affecting the acceptance of earth as sustainable building material in the United Kingdom. After carefully considering the nature of the research problem, an interpretivist philosophical stance was adopted to achieve the aim of this study.

Stage Two employed the Delphi technique consisting of an international expert panel of participants. They responded to a number of questions in two rounds and reached in a consensus on key factors affecting the acceptance of earth as a sustainable building material used addressing excessive global $\mathrm{CO}_{2}$ emissions. The Delphi Technique, essentially, was chosen as a primary research tool to extract scientific data to refine the list of factors (advantages, disadvantages and enablers) found in the literature review (data represented in Tables 1, 2 and 3). This form of methodology was selected to collect the data because of its capability to explore such factors. In particular, the Delphi technique is especially valuable where there is a lack of information and knowledge about an issue or phenomena (Adler \& Ziglio, 1996; Delbeq et al., 1975). This technique is very useful for investigating something not yet existing (Czinkota \& Ronkainen, 1997; Skulmoski \& Hartman 2002). The initial data collected from the Delphi technique, combined with the comprehensive literature review, produced a comprehensive list of consolidated and generic factors and provided a robust interview schedule for the validation phase (Stage Three) whereby a number of in-depth interviews was carried out with practitioners in the United Kingdom earth building with working experience.

Stage Three included in-depth interviews with the objective of further identifying and validating factors affecting the acceptance of earth as a sustainable material to cut down excessive $\mathrm{CO}_{2}$ emissions in the UK. In-depth interview method is suitable exploration in depth of new phenomena and collecting detailed information from someone's knowledge, thoughts and behaviour (Boyce and Neale (2006). Interviews are very useful of getting a clear picture and description of any issues or events of how, why and what happened. According to Mack et al (2005), this is a qualitative research method that is very efficient gathering data from someone's personal experience, feelings, opinions and 
helps learning about the perspectives of individuals. This validation phase with in-depth interviews, played an efficient part in acquiring delicate factors (such as unknown reasons) particularly from UK professionals, and enabled the researcher to compare factors identified from this stage, and the corresponding conceptual framework, with the factors and conceptual framework that emerged from stages one and two.

Stage Four included the summary and synthesis of the research findings, an acknowledgement of limitations, discussion of the contribution to knowledge brought about by the significance of the results to academia and the industry, and recommendations for future research. This stage facilitated a holistic understanding of the type of factors that may be affecting the acceptance of earth as a sustainable building material in the UK. As a way of increasing validity, each stage extracted essential data to assist and contribute to the development of subsequent stages.

\section{Understanding Generic Factors Affecting the Acceptance of Earth as Building Material Derived from the Delphi Method}

Globally there are few earth-building professionals/practitioners working, however, the most known of these were invited as participants in the Delphi method. Thirty-four professionals, that appeared to possess required knowledge on the phenomena, were contacted and invited from both the private and public sectors. Fourteen experts accepted the invitation (41\% response). All of them were construction professionals, practitioners and involved in some form of research and teaching. However, four of these participants did not respond during the second round of Delphi method. It is important to note that $50 \%$ of the Delphi participants were British. Two rounds of the Delphi were necessary for the panellists to reach a consensus. The Delphi method adopted for this research consisted of two rounds of questionnaires whereby the second round of questionnaires were built from questions and responses collected from the first round of questionnaires. Questionnaire of the first round was aimed to bring out the factors (advantages, disadvantages, and enablers) affecting the acceptance of earth as a sustainable building material. The second round of the Delphi technique summarised these factors from the previous round in ranked order and were sent back to the panellists for further contributions and refinement.

Three questions were asked during first round of the Delphi method:

$\checkmark$ What are the benefits of earth construction?

$\checkmark$ What are the drawbacks and inhibitors affecting the acceptance of earth as a building material?

$\checkmark$ What are the enablers that can help the acceptance of earth as a building material? In response to the first question, the experts expressed that earth construction is beneficial dependent on certain generic conditions and circumstances, such as the typologies of urban housing, the availability of suitable, locally sourced soil, appropriate climatic conditions, and the typologies of the stabiliser that is appropriate for this kind of construction. Twelve advantages of earth material were identified and outlined from the expert's feedback in the first round of the Delphi technique, which was less than the fifteen benefits identified during the search in literature. The feedback of the experts on the second question of the Delphi first round also revealed a diverse range of 
disadvantages influencing the acceptance of earth building. A total of twelve disadvantages were outlined from the expert's feedback, which was again less than the thirteen found during literature search. Furthermore, three of these factors were not included in the literature review. In response to the third question, six different categories of drivers were identified. Five of the drivers identified in the literature review (Table 3) were also identified in the first round of the Delphi by the experts, who also introduced one driver that was not previously mentioned in literature.

In response to the first question, the experts in round two agreed that earth, as a construction material is beneficial but dependent on the same conditions and circumstances (mentioned in the first round). They also verified the twelve benefits that were summarized in round one. Feedback on the second round of the Delphi further verified the twelve disadvantages that were outlined in round one. The experts also introduced two more disadvantages in the second round making it fourteen. Furthermore, in total, five additional disadvantages were outlined in the Delphi method that were not outlined during literature search. With regard to driving factors behind the acceptance of earth, the experts unanimously agreed with the six enablers established from round one and made no further comments.

Overall, in comparison with the literature review, the Delphi technique identified twelve benefits as opposed to fifteen, fourteen inhibitors and drawbacks as opposed to thirteen and six drivers as opposed to the five previously identified in literature. Taken together, all the factors (benefits, inhibitors/drawbacks and drivers) including the overlapped ones outlined in the Delphi method and the factors outlined during literature search may be used to reformulate an overarching conceptual framework that provides a clearer understanding of consolidated factors that may affect the acceptance of earth construction in general (Figure 3).
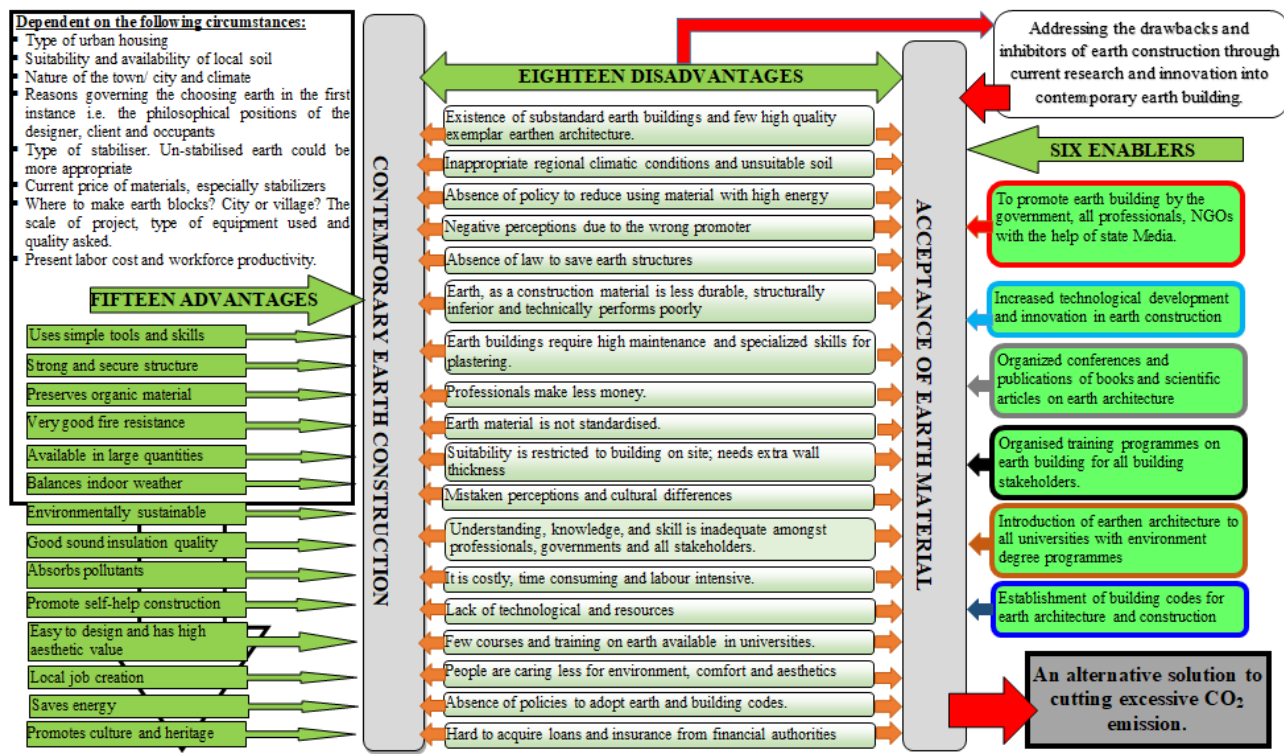

Figure 3: A conceptual framework of consolidated and generic factors affecting the acceptance of earth

Source: Author, 2020. 


\section{Factors Affecting the Acceptance of Earth as Sustainable Construction Material in the UK Derived from In-Depth Interviews}

In-depth interviews was aimed further refining and validating the consolidated and generic list of factors outlined from literature review and the Delphi technique with specific reference to the UK context. Earth construction experts are few, and small numbers of contemporary British earth building practitioners have practiced in the past or are working currently in the UK. However, data was gathered via face-to-face interview sessions with a number of participants from the private and public sectors. They had an average of over thirty-five years practice experience in earth construction. Participants were chosen from a specific set of criteria established to identify those with pertinent specialisation on the topic. Criteria are as follows:

- UK born and trained construction professionals, active members of various UK based international associations related to earth construction and knowledgeable in contemporary earth construction (i.e. to shed light on regional factors affecting the acceptance of earth material in the UK).

- Construction professionals not born in the UK but trained in the UK and who have worked internationally. They are aware of current form of earth buildings, and are able to analyse territorial factors with the help of their global knowledge on the topic.

In addition to verifying and validating the findings from the literature review and Delphi technique in the UK context, the experts were also given the freedom to explain their own statements and contribute to the list of factors (advantages, disadvantages and enablers). With regard to the benefits of earth construction, the interviewees agreed that earth is environmentally sustainable and beneficial in the UK context dependent upon certain conditions (see Figure 4). These conditions were different to those identified in the Delphi technique, such as; conditions of soil stabilisation dependent upon the classification of soil, skilled work force, project goal by the clients and availability of the soil on site (see Figure 3 for detail). The interviewees also recognised thirteen benefits of earth construction. Three benefits identified in the literature review and Delphi technique were not mentioned by the UK experts in this stage; however, the experts recognised a new benefit of earth construction that was not found in either the literature review or Delphi Technique.

A series of questions were also asked to validate and verify the inhibitors and drawbacks outlined from literature and Delphi method. The interviewees independently identified and later validated thirteen disadvantages of the thirteen outlined from literature and fourteen from Delphi technique. In other words, the UK experts did not mention the same thirteen disadvantages though they were outlined from literature search and Delphi method (see Figure 4). The interviewees, however, identified seven new disadvantages that were not acknowledged in the literature review or Delphi technique (see Figure 4). In the case of enablers, the interviewees were asked to identify potential enablers independently before validating those identified in the literature review and Delphi. Six enablers were validated and summarised from the interviews. Two drivers from the literature and Delphi were not mentioned by the UK experts, and two new drivers were identified in the in-depth interviews that were not found in the literature review or Delphi. A graphical presentation of interrelationships between disadvantages and 
enablers is presented in Figure 4. Overall, the in-depth interviews independently identified and validated factors (from the literature review and Delphi) affecting the acceptance of earth material in the context of the UK (i.e., thirteen advantages, thirteen disadvantages and six enablers). These factors, however, according to the experts, interact with each other and are interrelated. Based on these findings, Figure 4 presents a refined and reformulated conceptual framework of Figure 3. The reformulated conceptual framework illustrated in Figure 4 helps provides a clearer and more extensive understanding of the type of factors that may affect the acceptance of earth as sustainable material in the United Kingdom. However, some of the factors overlapped with the factors outlined from literature and Delphi method and rest independently identified considering UK context.
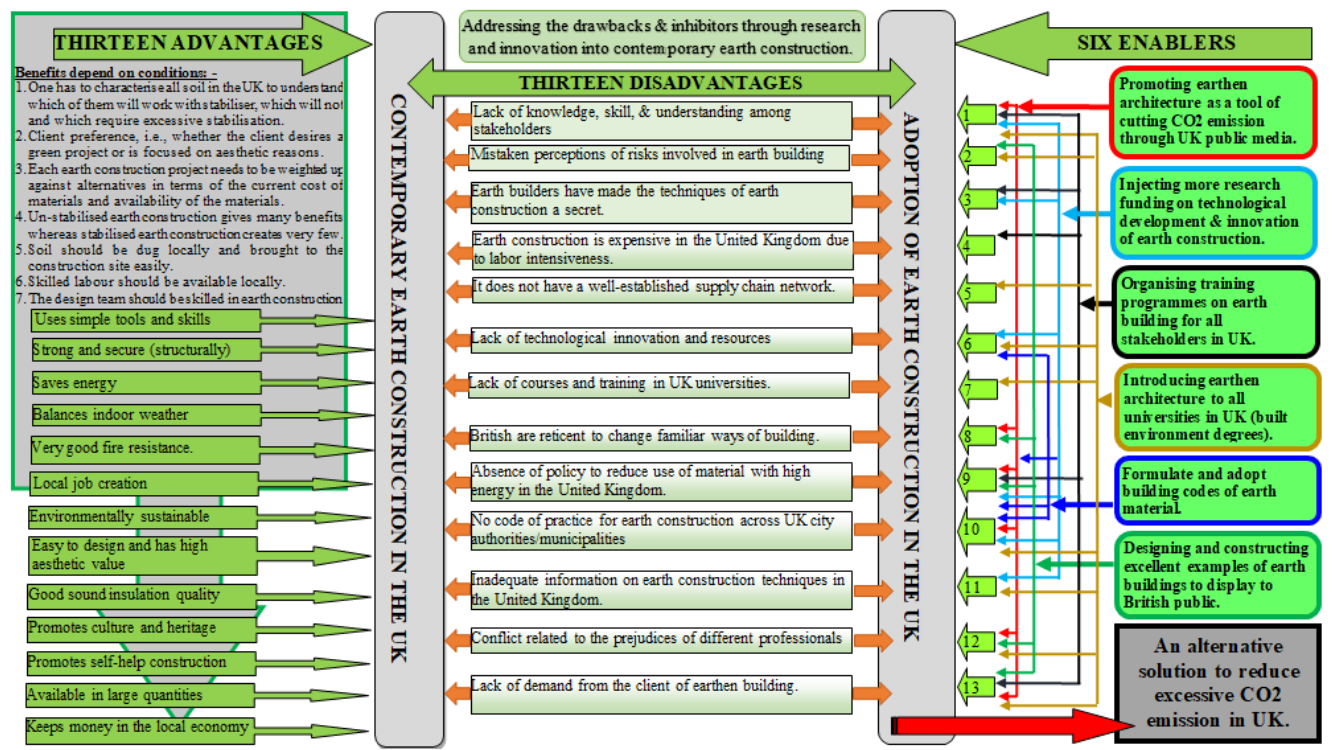

Figure 4: A conceptual framework to understand factors affecting the acceptance of earth material to reduce $\mathrm{CO}_{2}$ emissions in the United Kingdom

Source: Author, 2020.

\section{Contribution to the Knowledge}

This study adopted an interpretivist philosophical stance as a means of facilitating a comprehensive understanding of intervening factors that may affect the acceptance of earth as a sustainable material in the United Kingdom. Given that past research tended to account for factors that could be measured subjectively, (i.e., many of which lacked empirical evidence), an interpretivist philosophical stance was deemed most appropriate and effective in gaining a richer and deeper appreciation of how different interrelated factors may influence the adoption of earth materials in UK. Notwithstanding the value of this approach, the researcher accepts that there is benefit to conducting quantitative studies to test further the research outcomes. Since the remit of this study was limited to theory building, rather than testing and application, 
recommendations for future research in particular include application of this framework to develop/support sustainable construction policy in the national level. A notable contribution of this study, however, is the elicitation of current trends related to factors affecting the acceptance of earth building in the UK as informed from expert professionals. In addition, considering the complex nature of intervening factors (i.e., technological factors are directly and indirectly related to complex social phenomena) scope of the study could potentially be further expanded. However, it should be noted that the relevance of the factors identified in this study is apt to vary according to context.

As mentioned, in consideration of the exploratory nature of this study and the phenomenon under investigation, a four-stage research methodological framework was employed as a means of best addressing the aim and objectives established at the beginning of the research. Each phase of the study successfully extracted essential data to assist and contribute to the development of subsequent stages. Figure 5 presents a pictorial representation of the research process that was successfully carried out through the execution of a critical review of literature, the Delphi technique and in-depth interviews. The research process also importantly created an opportunity for the professionals involved in this study (i.e., practitioners and academics) to reflect on their experience working with earth material and to consider the challenging issues that they face on a daily basis laterally. Although it is not certain whether what was found in the research translates directly to practice due to the exploratory nature of the research design, the results provide valuable participant perspectives that bring greater awareness to intervening factors that affect the acceptance of earth building in the UK.

The final conceptual framework (Figure 4), presented in this study, integrates findings from the different stages of the research and, importantly, provides practitioners and policy makers a deeper understanding of how to more readily adopt earth construction, particularly as a means to addressing excessive $\mathrm{CO}_{2}$ emission. The framework also provides insight into pertinent issues surrounding the inhibitors and drawbacks of this technology, and how drivers may effectively counteract various drawbacks, i.e., such as how public media and good quality exemplar earthen architecture can be engaged to lead to the successful adoption of earth material in the UK. Although the value of the findings is contingent on how relevant the research is to individual construction professionals, and could be refined for future dissemination purposes, the results presented in this study provide valuable perspectives given difficulties in gaining access to the research subjects.

Construction, on a global scale, is a conservative pursuit for many reasons. Architecture professionals, for example, training for only 5 to 6 years predominantly based on knowledge from European and American modern movements. i.e., where concrete, burnt brick, glass and steel are prioritised as major construction materials. After such training, professionals put their knowledge into practice following existing building codes and regulations that predominantly relate to concrete, burnt brick, steel and glass construction. When faced with clients who prescribe earth as a construction material, architecture and building professionals can certainly find themselves ill-equipped. They may resist and reject the idea of working with earth, as it does not fit with their prescribed skill set. The same may be said for other professionals, such as civil, structural 
engineers, planners, building surveyors and technologists.

\section{LITERATURE REVIEW:}

A detailed literature search revealed the factors affecting the acceptance of earth are directly and indirectly linked to complex social phenomena. Considering the distinctive characteristics of the research philosophies and the nature of the problem under investigation, an interpretivist approach, with an epistemological assumption was chosen as the most appropriate yesearch philosophy for this study. The Nes ted Approach of the resenrch methodological design lead the atthor to adopt a particular approach in line with the interpretivism research philosophy i.e.,

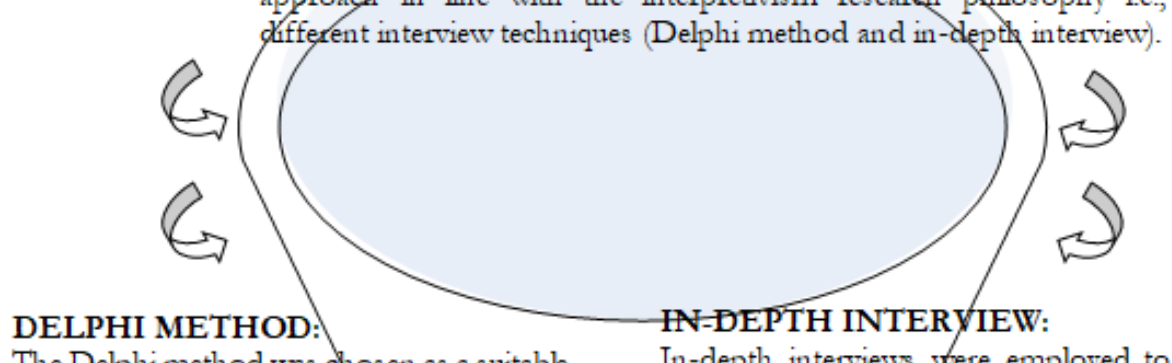

The Delphi method was chosen as a suitable approach because the resulte offered insight picture into present and hidden status of factors influencing the widespyead adoption of earth material. Two rounds of the Delphi were participated in by fourtean experts. The results of the Delphi technique were ranked to help the policy and decision makers prioritise which enablers could be implemented to overcome the dis advantages.

N-DEPTH INTERYIEW: factors factors summarised/from the literature search and Delphi methoo, es tablis hed expert opinions, and address delicate is sues that experts may have been hesitant to explain in front of an association. Experts knowledgeable in the UK context were fnterviewed through a number of unstructured open-ended questions to contribute, refine and validate factors summarised from the literature search and Delphi mether.

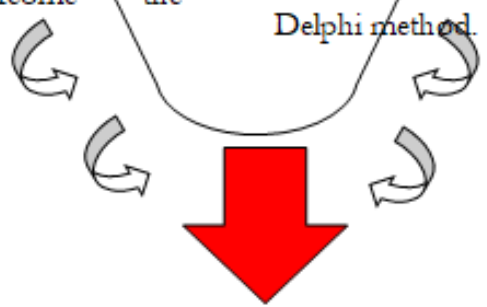

CONTRIBUTION OF THE STUDY: Outlining and understanding of the factors affecting the acceptance of earth material as environmentally sustainable to reduce excessive $\mathrm{CO}_{2}$ emission in United Kingdom.

Figure 5: A pictorial representation of the process of this study and contribution to knowledge Source: Author, 2020.

\section{Conclusions}

This study suggests that earth as a sustainable construction material is not yet widespread in the UK; yet, depending upon certain conditions, earth construction can be greatly beneficial in the UK context. As found in this study, the experts agreed on a total of thirteen potential benefits that the UK could take advantage of if earth was more 
readily adopted. Environmental benefits, in particular, are of major value, especially where the acceptance of earth building can help cutting excessive CO2 emissions in the UK.

At the same time, this study also identified thirteen inhibitors and drawbacks to adopting earth in the UK context, seven of which were not previously mentioned in literature. Five drivers, however, were also identified to possibly counter those drawbacks and support the acceptance of earth in the UK. Enablers such as promoting earth construction through public media, increasing research funding and effort into technological development and resources, introducing earth construction courses across UK universities, and constructing high quality iconic earthen architecture in the UK can significantly minimise the inhibitors identified in this study.

Overall, the conceptual framework presented in this study serves to help practitioners and policy makers in the construction industry better understand complex interrelationships between factors affecting the acceptance of earth construction, especially as a means of cutting excessive CO2 emissions in the UK. This study also formulated a consolidated and generic conceptual framework in the stages one and two respectively. In doing so, it compared the factors identified and conceptual frameworks formulated at different stages of this study that render a better understanding of how the adoption factors differ considering UK context. To date, several academic journal and academic conference publications around the world have been influenced because of this research. However, the target audience to gain most from this study includes: UK construction professionals and organisations, urban designers, planners, city council authorities and policy makers, i.e., those who have an interest in achieving the best out of environmentally, economically, and ecologically sustainable construction projects. The audience may also include contractors, supply chains, client organisations, politicians and trade unions.

\section{References}

Adams, Cassandra \& Elisabeth Lynne, 2005. "The realities of specifying environmental building materials", Alternative construction: contemporary natural building methods, ed. by Elizabeth Lynne and Cassandra Adams, New York (John Wiley and Sons, Inc.).

Adam, E. A. and Agib, A. R. A., 2001: Compressed Stabilised Earth Block Manufacture in Sudan, Paris (UNESCO).

Adler, M. and Ziglio, E. 1996: Gazing into the oracle: The Delphi Method and its application to social policy and public health, London (Jessica Kingsley Publishers)

Alphonse, S., 1985: General report, Appropriate Building Materials for Low cost Housing, African region. Proceedings of a symposium held in Nairobi, Kenya, 1983, London, New York, Volume II (E. and F. N. SPON,

Baiche, B.; Osmani M.; Hadjri, K. and Chifunda, C. 2008: Attitude towards earth construction in the developing world: a case study from Zambia. CIB W107 Construction in Developing World Countries International Symposium. "Construction in Developing countries: Procurement, Ethics and Technology." January 16-18, 2008, Trinidad and Tobago, West Indies.

Blondet, M. and Aguilar, Rafael 2007: Seismic protection of earthen buildings. International Symposium on Earthen Structures, Indian Institute of Science, Bangalore, August 22-24, year? (Interline Publishing)

Boyce, C. and Neale, P. (2006). Conducting In-Depth Interview: a guide for designing and conducting In-Depth Interviews for evaluation input. Pathfinder International Tool Series, monitoring and evaluation - 2. USA. http://www.pathfind.org/site/DocServer/m_e tool_series_indepth_interviews.pdf?docID=6301. 
Cassell, R. O. 1993: A traditional research paper: Rammed Earth Construction, The compaction of successive layers of earth between forms to build a wall. http://webs.ashlandctc.org/inapora/hum-faculty/syllabi/trad.html, access on 12.08.2007.

Castells, S. B. \& E. H. Laperal, 2007: Spanish architects working on earth. International Symposium on Earthen Structures, Indian Institute of Science, Bangalore, August 22-24, year? (Interline Publishing)

Chaudhury, S., 2007: Promotion of earthen structures in housing - the issue of "acceptability". International Symposium on Earthen Structures, Indian Institute of Science, Bangalore, August 22-24, year (Interline Publishing)

Czinkota, M. Ronkainen, 1997: International business and trade in the next decade: Report from a Delphi study. Journal of International Business Studies, 28(4), pp. 827-844.

Damme, Henri Van (2008). Terra Incognita? Terra Incognita preserving European earthen architecture, page 9. Argumentum, Culture Lab Edition. Culture 2000 programme. ISBN 978-972-8479-55-8, ISBN 978-2-9600527-4-9, Portugal.

Delbeq, A. \& A. Van de Ven \& D. H. Gustafson, 1975: Group techniques for program planning: A guide to nominal group and Delphi processes. Glenview, USA (Scott, Foresman and Company)

Easton, David, 1996: The Rammed Earth House, Vermont (Chelsea Publishing Company, White River Junction).

Eisenberg, D. 2005. A new context for building codes and regulation. Alternative construction: contemporary natural building methods. Edited by L. Elizabeth \& C. Adams. John Wiley \& Sons, Inc. New York, USA.

Elizabeth, L. 2005. The natural building movement. Alternative construction: contemporary natural building methods. Edited by L. Elizabeth \& C. Adams. John Wiley \& Sons, Inc. New York, USA.

Frescura, F. 1981. Rural Shelter in Southern Africa. Ravon Press, Johannesburg, RSA.

Habert, Guillaume (2018). Building to heal. International Symposium on Earthen Structures (ISES2018), Page 44. 22-24 August, 2018. JRD Tata Auditorium, National Institute of Advanced Studies (NIAS), Bangalore, India. Organised by the University of Bath, Coventry and Durham University, Universite De Lyon, Centre for Sustainable Technologies (CST), Indian Institute of Science (IIS), LEHM Project Team Dachverband Lehm e.V., KSCST, ENTPE. http://cst.iisc.ac.in/ises2018/

Hadjri, K., Osmani, M., Baiche, B. \& Chifunda, C. (2007). Attitude towards earth building for Zambian housing provision. Proceedings of the ICE institution of civil engineers, engineering sustainability 160 , issue ES3.

Houben, Hugo \& Hubert Guillaud, 1989: Earth construction, London (Intermediate Technology publications 1994).

Houben, H. et al 2007. Innovative approaches in educational pedagogy for earthen architecture. International Symposium on Earthen Structures, Indian Institute of Science, Bangalore, 22-24 August. Interline Publishing, India.

Howieson, S. 2005. Housing \& Asthma, Spon Press, ISBN 0-415-33646-5.

Jagadish, K. S., 2007: Earth construction today: prospects and tasks. International Symposium on Earthen Structures, Indian Institute of Science, Bangalore, 2007, pp. 22-24 August. (Interline Publishing)

Jayasinghe, C. (2018). Stabilised earth in load bearing walls and other applications. International Symposium on Earthen Structures (ISES2018), Page 34. 22-24 August, 2018. JRD Tata Auditorium, National Institute of Advanced Studies (NIAS), Bangalore, India. Organised by the University of Bath, Coventry and Durham University, Universite De Lyon, Centre for Sustainable Technologies (CST), Indian Institute of Science (IIS), LEHM Project Team Dachverband Lehm e.V., KSCST, ENTPE. http://cst.iisc.ac.in/ises2018/

Kateregga, J. K. 1983. Improvement and use of earth construction products for low cost housing. Appropriate Building Materials for Low cost Housing, African region. Proceedings of a symposium held in Nairobi, Kenya, 1983. Volume one. E. \& F. N. SPON, London, New York.

King, B. 1996. Buildings of earth and straw: structural design for rammed earth and straw-bale architecture. Ecological Design Press, California, USA.

Lal, A. K. 1995. Handbook of low cost housing. New Age International Publishers, New Delhi, India.

Linstone, H. \& Turoff, M. 1975. "Introduction" in the Delphi Method: Techniques and Applications Linstone and Turoff (Eds) Addison-Wesley Publishing Company, London. 
Mack, N., Woodsong, C., MacQueen, K. M., Guest, G. and Namey, E. (2005). Qualitative research methods: A data collector's field guide. USAID, Family Health International, North Carolina, USA.

Maini, Satprem, 2005: "Earthen architecture for sustainable habitat and compressed stabilised earth block technology", Programme of the city on heritage lecture on clay architecture and building techniques by compressed earth, High Commission of Ryadh City Development, India (The Auroville Earth Institute, Auroville Building Centre).

Meingast, R. \& Feiglstorfer, H. (2018). A conceptual framework by construction professionals to understand the factors influencing adoption of stabilised earth to address urban low cost housing crisis. Earth Construction and Tradition (Volume 2), page 28. ISBN 978-3-900265-37-3, Institute of History of Art, Building Archaeology and Restoration at the Vienna University of Technology in cooperation with IVA-ICRA the Institute of Comparative Research in Architecture. Print: Buchdrucker, Druck und Graphikservice GmbH, Hardeggasse 69, A-1220 Vienna, Austria.

Morris, J. \& Booysen, Q. 2000. Earth construction in Africa. Proceedings: strategies for a sustainable Built Environment, Pretoria, 23-25 August.

Minke, Garnot. 2006. Building with earth, design and technology of a sustainable architecture. Birkhauser publishers for architecture. Basel, Berlin, Boston.

Morton, Tom. 2007. Towards the development of contemporary Earth Construction in the UK: drivers and benefits of Earth Masonry as a Sustainable Mainstream Construction Technique. International Symposium on Earthen Structures, Indian Institute of Science, Bangalore, 22-24 August. Interline Publishing, India.

Ngowai, Alfred. B. 2000. The conflict between survival and sustainability. Proceedings: international conference sustainable building, 2000. 22-25 October, 2000. Maastricht: Netherlands.

Norton, John. 1997. Building with earth: A handbook (2nd edition). Intermediate Technology Publications, London, UK.

Reddy, B. V. Venkatarama (2018). Preface. International Symposium on Earthen Structures (ISES2018), Page X. 22-24 August, 2018. JRD Tata Auditorium, National Institute of Advanced Studies (NIAS), Bangalore, India. Organised by the University of Bath, Coventry and Durham University, Universite De Lyon, Centre for Sustainable Technologies (CST), Indian Institute of Science (IIS), LEHM Project Team Dachverband Lehm e.V., KSCST, ENTPE. http://cst.iisc.ac.in/ises2018/

Reddy, B. V. Venkatarama, Mani, Monto and Walker, Pete (2019). Preface, Earthen Dwellings and Structures: current status in their Adoption. Springer Transactions in Civil and Environmental Engineering. Page VII, INTRODUCTION, PAGE XXV. Springer Nature Singapore Pte Ltd. 2019. 152 Beach Road, \#21-01/04 Gateway East, Singapore 189721. https://www.springer.com/us/book/9789811358821

Robinson, S. (1939) "Houses Dirt Cheap." The Rotarian Aug. 1939: 24. United States. Department of Agriculture.

Skulmoski, G. J. \& Hartman, F. T. 2002: The Delphi method: Researching what does not exist (yet). Proceedings of the International Research Network on Organization by Projects, IRNOP V Conference, Renesse, the Netherlands.

Skulmoski, Gregory. J., Hartman, Francis. \& Krahn, Jennifer. 2007. The Delphi Method for Graduate Research. Journal of Information Technology Education Volume 6, pp. 1-22, California. http://jite.org/documents/Vol6/JITEv6p001-021Skulmoski212.pdf (Accessed 06.06.2009).

Sojkowski, J. 2002. Zambian Vernacular. Online paper, Architecture Week Website.

Walker, Peter; Keable, Rawland; Martin, J. \& Maniatidis, V. (2005). Rammed earth: Design and Construction Guidelines. BRE Bookshop, Zimbabwe.

Zami, M. S. (2011). Counterbalancing benefits and drawbacks of contemporary stabilised earth construction in urban low cost housing by the construction professionals. Archnet-IJAR, Volume 5, issue $2-$ July, International Journal of Architectural Research. Archnet @ MIT School of Architecture, Cambridge, Massachusetts, United States. PP. 49-62. ISSN \# 1994-6961. https://s3.amazonaws.com/media.archnet.org/system/publications/contents/5508/original/DP C2253.pdf?1384794192

Zami, M. S. (2014). Inhibitors and its intra-relationship influencing the adoption of stabilised earth construction to alleviate urban housing crisis in Zimbabwe. Open Access Library Journal (OALib Journal). DOI:10.4236/oalib.1100899, August 2014, Volume 1, e899. http://www.oalib.com/paper/3104540\#.V1fzbdIrLs0 
Zami, M. S. (2015). Drivers and their relationship with inhibitors influencing the adoption of stabilised earth construction to alleviate urban housing crisis in Zimbabwe. Key Engineering Materials (ISSN: 16629795), Vol. 632, Pages 119-144. Special volume on "Materials and Technologies for Green Construction". Published by Trans Tech Publications, Scientific.Net, Material Science and Engineering. doi:10.4028/www.scientific.net/KEM.632.119, Switzerland. http://www.scientific.net/KEM.632.119

Zami, M. S. (2018). A conceptual framework by construction professionals to understand the factors influencing adoption of stabilised earth to address urban low cost housing crisis. Earth Construction and Tradition (Volume 2), page 339-358. ISBN 978-3-900265-37-3, Institute of History of Art, Building Archaeology and Restoration at the Vienna University of Technology in cooperation with IVA-ICRA the Institute of Comparative Research in Architecture. Print: Buchdrucker, Druck und Graphikservice GmbH, Hardeggasse 69, A-1220 Vienna, Austria. 